\title{
Risk Model of Exposure to Air Pollution (No2, So2, TSP and Dust) on Pulmon Function in Traffic Police in Palembang City
}

\author{
Elvi Sunarsih, Suheryanto, Dwi Septiawati, Desheila Andarini, Rahmi Garmini
}

\begin{abstract}
Increasing volume in the vehicle lane it will increase the concentration of SO2, NO2, TSP, and Dust on the roadside both outdoor and indoor. The Police Officer of the Street Officers has a high level of exposure to motor vehicle gas emissions because they are people who throughout their work are always on the highway, so they will often be exposed and can interfere with health, especially the health of the respiratory system. The research aims to model air pollution exposure to lung function in traffic police. This study uses a cross sectional risk analysis design to estimate non cancer hazard index (HI) health risk by dividing the intake (I) value with References Concentration (RfC) and making a risk management model. Broadly speaking, the research was carried out in 4 important stages, namely, the first stage of the initial survey and field observations on 100 traffic police in Palembang City selected proportionally random sampling for the initial risk assessment data collection, the second stage Spirometry measurements and selected air sample data collection (NO2, SO2, TSP, Dust), and the third stage of laboratory analysis and spirogram reading, and the fourth stage Modeling of risk factors Exposure to air pollution to lung function capacity in Traffic Police. The average concentration of pollutants in the air $=N O 2: 0.478 \mathrm{mg}$ / m3; SO2: 0.856 mg / m3; TSP: 7.810 mg / m3; PM10: 3,591 mg / $m 3$. Lung capacity of traffic police, average FEV1: $2.81 \mathrm{~L}$ and FVC: 3.63 L. Realtime exposure assessment NO2: 0.055; SO2: 0.923; TSP: 2,943 and PM10: 4,8. The model of exposure to air pollution is needed to control the health effects of $\mathrm{NO2}, \mathrm{SO}$, TSP and PM10. Control modifies the standard or quality standard, where the HI value or Hazard Index that exceeds 1 can be controlled by controlling the intake value (I) inhalation of NO2, SO2, TSP and PM10
\end{abstract}

Index Terms: Lung Function, Lung Capacity, Risk Model, Traffic Police, Air Pollution

\section{INTRODUCTION}

The increase number of vehicles will affect the increase of vehicle exhaust emissions. According to the results of the (Keuken 2005) study with the title "Health Effects Of Transport-Related Air Pollution", it is stated that vehicle density in Europe has increased since 1990, followed by increased levels of air pollutants $\mathrm{CO}, \mathrm{NO} 2, \mathrm{SO} 2, \mathrm{~Pb}$ and $\mathrm{PM}$. The JICA (Japan International Cooperation Agency) study

Revised Manuscript Received on September 22, 2019.

Elvi Sunarsih, Universitas Sriwijaya., elvisunarsih@gmail.com

Suheryanto, Universitas Sriwijaya,

Dwi Septiawati, Universitas Sriwijaya

Desheila Andarini, Universitas Sriwijaya

Rahmi Garmini, STIKes Muhammadiyah Palembang in 1996 stated that the biggest contributor to pollutants in Jakarta came from vehicles. These pollutants include carbon monoxide (CO) by 58 percent, nitrogen oxide (Nox) 54 percent, hydrocarbons 88.8 percent, and lead $(\mathrm{Pb}) 90$ percent. Other pollutants are sulfur oxide (Sox), which is contributed by buses, trucks and other diesel-fueled vehicles, around 35 percent.

The impact of exposure to air pollution can occur in chronic or acute forms. In the short term, air pollutant gases ( $\mathrm{Pb}, \mathrm{NO} 2, \mathrm{SO} 2, \mathrm{TSP}$ and dust) can cause respiratory system disorders such as weakness, cough, shortness of breath, bronchopneumonia, pulmonary edema, and cyanosis and methemoglobinemia (MOH, 2011). According to (Raharjo 2009) the deviation effect from parameters of air pollution is could increase throat vessel reactivity and sensitivity in asthmatics. Air pollution is toxic especially to the lungs. Air pollution levels such as NO2 higher than 100 ppm can kill most experimental animals and $90 \%$ of these deaths are caused by symptoms of pulmonary swelling. Levels of $\mathrm{CO} 2$, $\mathrm{SO} 2, \mathrm{NO} 2$ of $800 \mathrm{ppm}$ will result in $100 \%$ mortality in animals tested within 29 minutes or less. Exposure of NO2 to a level of $5 \mathrm{ppm}$ for 10 minutes to humans results in difficulty in breathing (MOH, 2010 in sunarsih 2015).

One method that can be used to determine the effects of air pollution on health is to use the method of environmental health risk analysis (ARKL). Environmental Health Risk Analysis (ARKL) is a method that can formulate risk control more specifically, both qualitatively and quantitatively. The ARKL aims to provide a scientific framework for decision makers and people who care to eliminate health problems especially that related to environmental case (Louvar, J.F. 1998).

The Police Officer of the Street Officers has a high level of exposure to motor vehicle gas emissions because they are people who throughout their work are always on the highway, so they will often be exposed and can interfere with health, especially the health of the respiratory system. This can be shown in the decline in pulmonary physiological function that will arise for years after exposure (Haliim, 2011). The research aims to model air pollution exposure to lung function in traffic police. 


\section{LITERATURE REVIEW}

Air pollution exposure such as SO2, PM10, TSP, SO2, and $\mathrm{NO} 2$ have been related with many adverse health effects, such as cardiovascular disease, respiratory disease, and total mortality (Hooven 2012). Urban ambient air pollution is the result of emissions from a multiplicity of sources, mainly stationary, industrial, and domestic fossil fuel combustion and petrol and diesel vehicle emissions. The magnitude of effect estimates vary across cities and countries hindering interpretation and generalization of the causal association between air pollution and health.

SO2 levels are dangerous because it slowly adsorbs on fine atmospheric particles and can be transported very deep into lungs and therefore staying there for a long time. Due to their very long residence time and acidic character, they can cause serious damage to the lung tissue (edema). NO2 is a deep lung irritant, which has been shown to generate biochemical alterations and histological demonstrable lung damage in laboratory animals as a result of both acute and chronic exposure. Inhaled NO2 can penetrate to small lung airways, and hence, there is much greater susceptibility with $\mathrm{NO} 2$ to broncho-constrictive response in individuals with asthma (Singh 2010).

Total suspended particulates (TSPs) are general term used for a mixture of solid particles and liquid droplets found in the air. These particles, come in a wide range of sizes, originates from many different stationary and mobile sources as well as from natural sources. These suspended particles vary in size, composition, and origin. This includes all airborne solid and liquid particles, except pure water. Biomass burning, combustion of fossil fuels, and oxidation of hydrocarbons are the major sources of atmospheric CO. Carbon monoxide interferes with oxygen uptake into the blood, heart, and brain damage impaired perception, asphyxiation, weakness, headache, and nausea (Rabee Adel 2015)

\section{METHODOLOGY/MATERIALS}

\section{A. Study Design and Sampling Procedure}

This research is descriptive research using quantitative analysis method, using cross sectional design (cross sectional) with hypothesis testing. Then a risk analysis is performed to estimate non cancer hazard index (HI) health risk by dividing the intake (I) value with References Concentration (RfC) and making a risk management model. The location of this research is in the city of Palembang. The population of this study is all Traffic Police in Palembang City. The sampling unit is Traffic Police with high risk population and the research sample is Traffic Police in Palembang City.

The sample will be taken using a purposive sampling technique. The minimum sample size needed in this study will be calculated using the sample size formula to test the hypothesis of estimating the proportion of simple random sampling for the finite population (Lemeshow, 1997). The number of samples to be taken is fulfilled so that the total sample to be taken is 100 respondents. In sampling at the terminal researchers used proportional random sampling method, which is to divide the number of samples proportionally in each District (16 Districts)

\section{B. Instrument Development and Data Collection Procedure}

Broadly speaking, research is carried out in 4 important stages.

The first phase of the initial survey and field observations in the study population for the initial data collection of risk studies. This initial survey also identified symptoms of respiratory problems in one of the analysis units randomly. At this stage there was also recruitment and training for 4 survey officers who would survey 100 respondents. In addition, language transfer and ST duplication were also carried out. George's Respiratory Questionnaire (SGRQ).

The second stage was interview respondents, Spirometry measurements and selected air sample data collection (NO2, $\mathrm{SO} 2$, TSP, Dust). At this stage interviews were conducted with respondents using a standard questionnaire adopted from ST. George's Respiratory Questionnaire (SGRQ). Then NO2 samples were taken in the class (indoor air) to determine the $\mathrm{NO} 2$ concentration in the class with the Impinger Gas Sampler. Besides that, lung capacity function (FEV1 \& FVC) was measured in each respondent.

The third stage is laboratory analysis and spirogram reading. Laboratory analysis was carried out on class air samples that had been taken in the previous stage. The test method used based on SNI 19-7119.2-2005 concerning Test Method for Nitrogen Oxides (NO2, SO2, TSP and PM10) by the Griess Saltman method using a spectrophotometer. Materials and tools used in the analysis of concentrations of NO2, SO2, TSP and PM10 were spectrophotometers, absorbance of $\mathrm{NO} 2, \mathrm{NO} 2$ standard solutions, and aquabides. NO2 concentration will determine the value of health risk by comparing it with References of Concentration NO2(EPA. 1992).

Fourth stage is modeling of risk factors Exposure to air pollution to lung function capacity in Traffic Police. At this stage, health risk estimation, health risk factor modeling and risk control model simulation are carried out. Estimation of health risks in the form of calculation of non-cancer risk, namely non cancer hazard index (HI). Risk factor modeling is done to determine the effect of factors that affect the function of lung capacity. Then proceed with making a risk management model simulation by taking into account the results of the hypothetical model through the validity of the mathematical theory that was stated earlier.

\section{Ethical Considerations}

This research has received ethical approval from the Research Ethics Commission of the Faculty of Public Health, Sriwijaya University. 


\section{Data Processing and Analysis}

In this study data analysis was divided into two parts, Health Risk Analysis and Hypothesis Test Statistical Analysis. Health Risk Analysis for Nitrogen Dioxide (NO2) is determined as a systemic non-carcinogenic effect, expressed as a Noncancer Hazard Index (HI). HI is enforced by combining the results of the exposure analysis with dose-response analysis. Exposure analysis is used to calculate the dose or amount of risk agent NO2 received by individuals and expressed as intake or intake (I). Then the rate of inhalation of RfC from the EPA standard for $\mathrm{NO} 2$ is used to calculate the risk of $\mathrm{HI}$ by conducting a comparison of the level of exposure for a given time (I) with the reference dose for the same exposure (RfC). Then a risk control model simulation is made. Statistical analysis was conducted to test whether predictions made through Health Risk Analysis have caused symptoms or not. Test Analysis This hypothesis is also called the EKL survey (Epidemiology of Environmental Health). Statistical analysis carried out in univariate, bivariate, and multivariate. To prove the hypothesis of the factors that influence the lung capacity function test (FEV1 and FVC), carried out by logistic regression analysis because the dependent variable lung capacity test FEV1 and FVC is a categorical variable (categorized) and the independent variable is a category variable. Chi Square test was used to examine the relationship between lung capacity function (FEV1 and FVC) with the value of non-cancer risk. Chi Square test is used to test the relationship between lung capacity function (FEV1 and FVC) with complaints of respiratory tract disorders.

\section{RESULTS AND FINDINGS}

\section{A. Concentration of Pollutants in the Air}

The results of measuring the concentration of pollutants in the air:

1. The average concentration of $\mathrm{NO} 2$ in the air is 0.478 $\mathrm{mg} / \mathrm{m} 3$

2. The average concentration of $\mathrm{SO} 2$ in the air is 0.856 $\mathrm{mg} / \mathrm{m} 3$

3. The average TSP concentration in the air is $7.810 \mathrm{mg}$ / $\mathrm{m} 3$

4. The average concentration of PM10 in the air is 3.591 $\mathrm{mg} / \mathrm{m} 3$

Lung Capacity of Traffic Police

Table 1:Distribution of Pulmonary Capacity Indicator in

Traffic Police

\begin{tabular}{llll}
\hline \multirow{2}{*}{ Information } & \multicolumn{2}{l}{ Pulmonary Capacity } \\
\cline { 2 - 4 } & FEV1(L) & FVC (L) & $\begin{array}{l}\text { FVC Prediksi } \\
(\mathrm{L})\end{array}$ \\
\hline Min & 1,48 & 2,58 & 1,48 \\
\hline
\end{tabular}

\begin{tabular}{llll}
\hline Max & 4,33 & 4,11 & 4,24 \\
Mean & 2,81 & 3,63 & 2,69 \\
Median & 2,69 & 3,68 & 2,65 \\
Deviation Std & 0,56 & 0,35 & 0,51 \\
\hline
\end{tabular}

The pulmonary capacity of the traffic police gets the forced expiration volume value at the first second (FEV1) having an average of $2.81 \mathrm{~L}$ with the lowest value is $1.48 \mathrm{~L}$ and the highest value is $4.33 \mathrm{~L}$. As for the value of forced Vitas capacity ( FVC) ranges from $2.58 \mathrm{~L}$ to $4.11 \mathrm{~L}$ with an average of $3.63 \mathrm{~L}$. The predicted value of FVC that has been adjusted to Indonesian standards has a mean that is not much different, which is $1.52 \mathrm{~L}$.

\section{B. Exposure Assessment}

The assessment of exposure in getting the lowest NO2 inhalation intake was $0.001 \mathrm{mg} / \mathrm{kg} /$ day and the largest intake was $0.055 \mathrm{mg} / \mathrm{kg} /$ day. The lowest SO2 inhalation intake was $0.001 \mathrm{mg} / \mathrm{kg} /$ day and the largest intake was $0.099 \mathrm{mg} / \mathrm{kg} / \mathrm{day}$. The lowest TSP inhalation intake was $3.118 \mathrm{mg} / \mathrm{kg} /$ day and the largest intake was $10.221 \mathrm{mg} / \mathrm{kg}$ / day. The lowest PM10 inhalation intake is $0.007 \mathrm{mg} / \mathrm{kg}$ / day and the largest intake is $0.413 \mathrm{mg} / \mathrm{kg} / \mathrm{day}$. Exposure assessment using realtime exposure is $\mathrm{NO} 2$ of $0.055, \mathrm{SO} 2$ of 0.923 , TSP of 2.943 and PM10 of 4.8 .

\section{Risk Assessment}

Non-cancer risk assessments are calculated in realtime with the duration of time according to reality. Calculation of the intake of NO2, SO2, TSP, PM10 with realtime time on traffic police in the city of Palembang using agent concentration; where the concentration is NO2 levels at the Palembang City police post ranged from $0.248 \mathrm{mg} / \mathrm{m} 3$ to $0.610 \mathrm{mg} / \mathrm{m} 3$ with an average of $0.478 \mathrm{mg} / \mathrm{m} 3$, the concentration of SO2 levels ranged from $0.705 \mathrm{mg} / \mathrm{m} 3$ to $0.610 \mathrm{mg} / \mathrm{m} 3$ with an average of $0.854 \mathrm{mg} / \mathrm{m} 3$, the concentration of TSP levels ranged from $3.118 \mathrm{mg} / \mathrm{m} 3$ to $10.221 \mathrm{mg} / \mathrm{m} 3$ with an average of $7.811 \mathrm{mg} / \mathrm{m} 3$, and the concentration of PM10 levels ranged from $2.118 \mathrm{mg} / \mathrm{m} 3$ to $5.812 \mathrm{mg} / \mathrm{m} 3$ with an average of $3.594 \mathrm{mg} / \mathrm{m} 3$.

\section{Exposure Pattern Assessment}

After knowing the value of the agent, the assessment of the subsequent exposure pattern is done by determining the exposure path, the frequency of exposure, the length of exposure, and the route or path of exposure. Assessment of exposure frequency, exposure time / duration, and duration of exposure in this study was obtained from direct calculation of data. While the exposure pathways of NO2, SO2, TSP and PM10 in this study through inhalation. The average exposure time is 10 hours / day. Then for the frequency of exposure (days / years) obtained from the minimum value of the exposure frequency of 180 days / year and the minimum duration of exposure of 1 year to traffic police in the city of Palembang.

\section{E. Respondent Anthropometry}

Anthropometric 
characteristics are seen from two indicators, namely police weight, traffic and inhalation rate.

The average weight of the respondent is $79.68 \mathrm{~kg}$ with the lowest value being $50 \mathrm{~kg}$ and the highest value of $121 \mathrm{~kg}$. The inhalation rate in this study is used as a standard from the Environmentas Protection Agency (EPA). By taking the value of inhalation rate on long-term exposure levels 31-41 years, the recommended inhalation rate is $16 \mathrm{~m} 3$ / day. After unit conversion, the hourly inhalation rate is $0.66 \mathrm{~m} 3$ / hour which will be used in this study.

\section{F. Response Dose Analysis}

The quantitative value of toxicity needed for risk characteristics is NOAEL or LOAEL derived from the bioassay test and epidemiological studies. In this study the value of References Concentration (RfC) for $\mathrm{NO} 2$ was obtained from the standard U.S EPA which was $0.02 \mathrm{mg} / \mathrm{kg}$ / day. While the value of References Concentration (RfC) from SO2, TSP and PM10 is not yet available in the EPA flat Integreted Risk Information System (IRIS) or the Minimum Risk Level ATSDR table, so it uses the RfC value from previous studies. RfC SO2, TSP and PM10 are not determined from the dosage used to cause the lowest effect or NOAEL and LOAEL but are derived from National Ambient Air Quality Standard (NAAQS) which is the ambient air quality standard by US-EPA where the national quality standard for ambient air according to PP No.41 of 1999 cannot be used because the default value of the exposure factors is unknown.

\section{G. Risk Characteristics}

Risk characteristics, obtained from two research sections, namely exposure assessment and dose-response assessment. Where the lowest NO2 inhalation intake was $0.001 \mathrm{mg} / \mathrm{kg}$ / day and the largest intake was $0.055 \mathrm{mg} / \mathrm{kg} / \mathrm{day}$. The lowest SO2 inhalation intake was $0.001 \mathrm{mg} / \mathrm{kg} /$ day and the largest intake was $0.099 \mathrm{mg} / \mathrm{kg} /$ day. The lowest TSP inhalation intake was $3.118 \mathrm{mg} / \mathrm{kg} /$ day and the largest intake was $10.221 \mathrm{mg} / \mathrm{kg} /$ day. The lowest PM10 inhalation intake is $0.007 \mathrm{mg} / \mathrm{kg} /$ day and the largest intake is $0.413 \mathrm{mg} / \mathrm{kg} /$ day.

\section{DISCUSSION}

\section{A. Total Suspended Particulate (TSP) concentration in the Police Post Work Environment}

TSP (Total Suspended Particulate) or Particulate Floating dust is a mixture of various organic and inorganic compounds measuring < 1 micron to 500 microns. The dust particulate will float in the air and can enter the human body through the respiratory tract $(\mathrm{MOH}, 2003)$. Naturally particulate dust can be produced from dry soil dust carried by the wind or from vomit volcanic eruptions. Incomplete combustion of fuel containing carbon compounds will be pure or mixed with organic gases as well as the use of diesel engines that are not well maintained ( $\mathrm{MOH}, 2003)$.

TSP levels can endanger health because it can cause obstruction or restriction from the airways. While the parameters although in small amounts and far below the standard can still be dangerous if inhaled for a long period of time. This is of course very influential on lung health Traffic Police who have worked for 8 hours every day while they work very long in the field.

\section{B. Concentration of Dust Particulate Matter (PM 10) in the Police Post Environment}

Based on its aerodynamic size, PM10 is a pollutant particulate that is easily suspended for a considerable amount of time in the air so that the tendency of workers to breathe air containing these particulates is greater than for particulates with other aerodynamic sizes. When inhaled, particulates will irritate mucociliary epithelial cells in the nasal cavity, giving rise to an immunological response to mucous secretions which can be called allergy rhinitis. When particulates enter deeper organs, they cause irritation to other respiratory organs and cause other immunological responses such as coughing, sore throat and fever. This collection of symptoms is a symptom of acute respiratory distress.

In this study dust is a strong risk factor for lung function disorders. Research at the Yogyakarta terminal conducted by BBTKL Yogyakarta (2007) also stated that there was a relationship between the concentration of ambient dust and the risk of lung dysfunction in which the higher the concentration of ambient dust, the higher the risk of lung dysfunction. In the study conducted by the BBTKL, it was found that PM10 was more influential than total dust (TSP).

\section{Concentration of Sodium Dioxide (NO2) in the Police Post Environment}

When compared with the Governor Regulation No. 17 of 2005 concerning ambient air quality standards, both the highest concentration value and the average concentration value obtained, overall it is above the environmental quality standard, which is $400 \mu \mathrm{g} / \mathrm{Nm} 3$ / 1 hour for NO2 hunting. done for one hour. The effect of NO depends on the level and duration of exposure, exposure to $\mathrm{NO} 2$ of $50 \mathrm{ppm}$ can result in coughing, hemoptysis, dyspnea, and chest pain. If exposure to NO2 is higher than $100 \mathrm{ppm}$, it can produce pulmonary edema which is fatal or can cause bronchiolitis obliterans. Several studies have shown that chronic exposure to NO2 can affect individuals for the development of chronic lung disease, including infection and obstructive pulmonary disease

\section{Sulfur Dioxide (SO2) Concentration In The Police Post Environment}

SO2 emissions come from the oxidation of sulfur contained in diesel fuel which is the main fuel of bus vehicles. The sulfur content in fuel affects the amount of SO2 released into the environment. The high volume of buses operating in the terminal at one time and the high sulfur content in diesel fuel consumed is important to

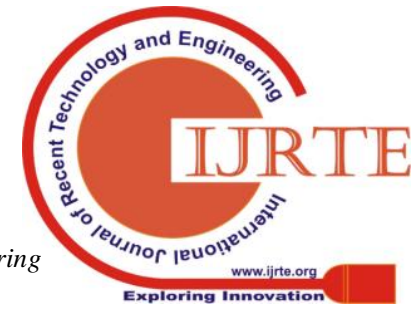


study how much SO2 emissions are produced and how the impact on the air environment conditions in the terminal is an effort to protect the environment and public health especially those activity in the terminal from the negative impact of $\mathrm{SO} 2$ emissions. In addition to this, efforts to monitor the air quality of the road environment both through studies and routine monitoring have been minimal, so that the tools for evaluating the negative impacts caused by the operation of vehicles on highways are very limited (The Ministry of Health 2011).

Ambient air contaminated by SO 2 gas can certainly have a negative impact on living things that live around it. For humans $\mathrm{SO} 2$ gas can cause an irritating effect on the upper respiratory tract because it easily dissolves in water which results in increased mucus production resulting in narrowing of the respiratory tract (Sandra 2013). In certain concentrations SO2 gas can cause lung disease and difficulty breathing, especially for people with asthma, bronchitis, and other respiratory diseases. In addition, SO2 gas is very dangerous for living things because it plays an important role in the accumulation of acid in the air which causes acid blast. SO2 gas can also damage plants at levels of $0.5 \mathrm{ppm}$ (Azizah and Zakaria 2013).

\section{E. Overview of Lung Capacity in Traffic Police}

The results of this study indicate that the Forced Execution Volume value at the first second (FEV1) has an average of $2.81 \mathrm{~L}$ with the lowest value is $1.48 \mathrm{~L}$ and the highest value is $4.33 \mathrm{~L}$. As for the value of Forced Vital Capacity (FVC) ranges between $2.58 \mathrm{~L}$ and $4.11 \mathrm{~L}$ with an average of $3.63 \mathrm{~L}$. The predictive value of FVC that has been adjusted to Indonesian standards has a mean that is not much different at $3.42 \mathrm{~L}$, for the univariate results analyzed there are $47,4 \%$ of respondents who experience lung capacity disorders while those who have normal lung as many as $52.6 \%$ of respondents.

Based on the observations of researchers, the place where the traffic police are in charge is that they are more often on the road and also cause the air pollution is very high besides the factor of every individual who still smokes on the break, resulting in a decrease in lung function in FEV1. In addition, the traffic police in their daily duties are still very rarely using personal protective equipment in the form of masks, this is because there are still many traffic police who do not know the danger of exposure to pollution in the long term. Even though using a mask can reduce exposure to pollution that enters the body.

\section{F. Intake (intake) on Traffic Police}

Ambient air and indoor air are sources of potential toxic substances. Adults and children can be exposed to air contaminated with various pollutants during various activities in different environments. They may be exposed to contaminants in the surrounding air and may also breathe chemicals from various sources in the room (stoves, heaters, fireplaces and consumer products) as well as from infiltrating from the surrounding air.

\section{G. Length of Exposure to Traffic Police}

According to Act No. 13 of 2003 concerning manpower, it is explained that working hours allowed for workers are 8 hours / day. In fact there are still many workers exposed to more than 8 hours / day. Based on univariate analysis, it was found that workers exposed to more than 8 hours / day were more $(80.7 \%)$ compared to workers exposed to less than 8 hours / day.

The results of bivariate analysis showed that the length of exposure was not related to lung capacity ( $p>0.05)$, that is, $p$ $=0.386$ can be interpreted that there was no relationship between the length of exposure and lung capacity in traffic police. From the results of data processing carried out it was noted that the average value of the length of exposure to the traffic police at the police station was 11 hours / day. But if the exposure time is seen per respondent it turns out the results are very diverse. Where there are police whose total working hours are under 8 hours / day but there are also police whose total working hours exceed 8 hours / day.

\section{H. Frequency of exposure to traffic police}

The results of bivariate analysis showed that the exposure frequency was related to lung capacity $(\mathrm{p}<0.05)$, that is, $\mathrm{p}=$ 0,000 can be interpreted that there was a relationship between the frequency of exposure and lung capacity in traffic police. The average (median) frequency of traffic police exposure is 349 days / year.

\section{Exposure Duration in Traffic Police}

The duration of exposure is the length of time the respondent is exposed to pollutants in units of years. In this study the duration of exposure values used were estimated values based on real time values obtained by measuring the duration of adult exposure. The duration of exposure used is real time, 5 years, 10 years, 15 years, 20 years, 25 years and 30 years.

In this study 10-year projections were used in accordance with the average (median) duration of exposure to traffic police at the police station to determine the estimated occurrence of health risks due to exposure to pollutants. The duration of exposure influences the level of risk, besides being influenced by the length of the duration of exposure, the level of risk is also influenced by the concentration of pollutants in ambient air, intake rate, frequency of exposure and weight of the respondent. This has an effect on the estimation of how long the respondent is likely to be exposed to health risks caused by exposure to pollutants. The results of bivariate analysis showed that the duration of exposure was not related to lung capacity ( $p>0.05)$, that is, $p$ $=0.156$, meaning that there was no relationship between the duration of exposure and lung capacity in traffic police.

\section{J. Non-Carcinogenic Risk Level (RQ) in Traffic Police}

This Environmental Health Risk Analysis Study (ARKL) examines Risk Quetient (RQ) according to the concentration of risk agents at the Jakabaring Police Post, Fountain Water

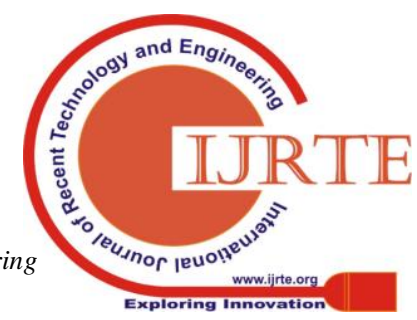


Post, Force 66 Police Post, Simpang Charitas Police Post, Simpang IP Police Post, Police Post Simpang Sekip, Pos Simpang Patal Police and Simpang PoldaPalembang Police Post, respondents taken based on the sampling collection area, were traffic police working in the area of the police post.

From the test results it is known that at present there are respondents who have $\mathrm{RQ} \geq 1$ which means that there are respondents who have a risk of exposure to TSP, PM10, NO2 and SO2. This is in line with Fatonah's research (2010) which shows that the longer the estimated time, the more respondents have $R Q \geq 1$. But it is not in line with the research of Haryoto (2014) which divides the research location into 3 locations resulting in a cluster of 23 more respondents who have an unsafe risk. As we know the duration of exposure has a straight ratio with intake, while body weight has an inverse ratio with intake. Risk level (RQ), in addition to risk agent concentration, anthropometry (body weight and age), and activity patterns (intake rate, duration of exposure and time of exposure), another variable that is very influential in determining the level of risk is reference concentration (RfC).

\section{CONCLUSION}

The model of exposure to air pollution is needed to control the health effects of NO2, SO2, TSP and PM10. Control modifies the standard or quality standard, where the HI value or Hazard Index that exceeds 1 can be controlled by controlling the intake value (I) of inhalation NO2, SO2, TSP and PM10 because the RfC value is derived from experimental data that cannot be modified (because as a referral). So what must be lowered so as not to have an impact on health is the value I where the average value of $I$ is 0.038 and the highest value is 0.056 . To reduce the value of I at the received RfC level which is 0.02 can be used the same equation from the non-cancer risk analysis equation. If currently the respondent is 16 years old, there will be approximately 2 years for respondents to be exposed to exposure to NO2, SO2, TSP and PM10 assuming that for two years they do not stop or change jobs.

\section{ACKNOWLEDGEMENTS}

Thank you to the research institute and community service of Sriwijaya University as a provider of research funds. Thank you also to all those who helped

\section{REFERENCES}

[1] Azizah and Zakaria. 2013. "Analisis Pencemaran Udara, Keluhan Iritasi Tenggorokan Dan Keluhan Kesehatan Iritasi Mata Pada Pedangan Makanan Di Sekitar Terminal Joyo Boyo." Journal of Occupational Safety and Health. 2(1):75-81.

[2] EPA., US. 1992. Federal Register - Guidelines for Exposure Assessment; Notice. Washington, DC,: US Environmental Protection Agency.

[3] Hooven, Edith H. Van den et. al. 2012. "Air Pollution Exposure Estimation Using Dispersion Modelling and Continuous Monitoring Data in a Prospective Birth Cohort Study in the Netherlands. .." Environmental Health 11(9).

[4] Keuken. 2005. Health Effects Of Transport-Related Air Pollution. Denmark.
[5] Louvar, J.F., B. D. Louvar. 1998. Health and Environmental Risk Analysis : Fundamental with Application. New Jersey: Prentice Hall.

[6] Rabee Adel. 2015. "Estimating the Health Risks Associated with Air Pollution in Baghdad City, Iraq." Environ Monit Assess 187(4023).

[7] Raharjo. 2009. "The Effect of Air Pollution and Human Health." Universitas Diponegoro.

[8] Sandra. 2013. "Effect of Decreasing Air Quality on Lung Function and Respiratory Complaints on Traffic Police in Surabaya." IKESMA 9(1):2-7.

[9] Singh. 2010. "Study of Temporal Variation in Ambient Air Quality during Diwali Festival in India." Environ Monit Assess 169:1-13.

[10] The Ministry of Health. 2011. Air Pollution Parameters and Their Impacts on Health. Jakarta.

\section{Authors Profile.}

Elvi Sunarsih currently affiliated with the Universitas Sriwijaya. My area of interest is environmental sustainability.

Suheryanto I am from Universitas Sriwijaya. My area of interest is sustainability.

Dewi Septiawati from the Universitas Sriwijaya. My area of interest is sustainability.

Desheila Andarini from Universitas Sriwijaya. My area of interest is sustainable environment managment.

Rahmi Garmini, STIKes Muhammadiyah Palembang. My area of interest is sustainability. 